\title{
CORRIGENDA
}

\section{Dating the cyanobacterial ancestor of the chloroplast}

\author{
Luisa I Falcón, Susana Magallón and Amanda Castillo
}

The ISME Journal (2011) 5, 366; doi:10.1038/ismej.2010.98

Correction to: The ISME Journal (2010) 6, 777-783; doi:10.1038/ismej.2010.2

Since the publication of this paper, the authors have noticed an omission in the acknowledgements section. The missing text is as follows.
LIF, SM and AC were funded by SEP-CONACyT (Mexico), projects no. 56045 (LIF) and 2004-C0146475-Q (SM, AC), respectively. LIF was funded by PAPIIT, project no. IN225709-3.

The authors would like to apologize for this error.

\section{Unraveling the viral tapestry (from inside the capsid out)}

\author{
Shawn W Polson, Steven W Wilhelm and K Eric Wommack
}

The ISME Journal (2011) 5, 366; doi:10.1038/ismej.2010.122

Correction to: The ISME Journal (2011) 5, 165-168; doi:10.1038/ismej.2010.81; published online 17 June 2010

Since the publication of this paper, the authors have noticed an omission in their article. The missing text is shown here.

\section{Acknowledgements}

The authors are grateful to the Scientific Committee for Ocean Research (NSF grant OCE-0608600), the Gordon and Betty Moore Foundation and the NSF Delaware EPSCoR program for supporting the scientific meeting of the SCOR Working Group on the Role of Viruses in Marine Ecosystems (WG126). Ideas behind our commentary came from work associated with National Science Foundation grants (MCB 0731916, EF 0626826, OCE 0851113 and OCE-0825405) and the National Research Initiative Competitive Grant award (2005-35107-15214) from the US Department of Agriculture Cooperative State Research, Education, and Extension Service. 